\title{
ECONOMÍA DEL COMPORTAMIENTO: PASADO, PRESENTE Y FUTURO*
}

Richard H. Thaler

* DOI: https://doi.org/10.18601/01245996.v20n38.02. Este artículo se basa en el discurso presidencial en la reunión de la American Economic Association realizada en enero de 2016, publicado en American Economic Review, 106(7), 1577-1600, y en mi libro reciente Misbehaving: The making of behavioral economics, que contiene una bibliografía mucho más extensa. Se publica con las autorizaciones correspondientes. Traducción de Alberto Supelano. Recepción: 07-09-2017, aceptación: 19-02-2018. Sugerencia de citación: Thaler, R. H. (2018). Economía del comportamiento: pasado, presente y futuro. Revista de Economía Institucional, 20(38), 9-43.

a Profesor Robert P. Gwinn de Ciencia y Economía del Comportamiento y director del Centro de Investigación de las Decisiones de la Escuela de Negocios, Universidad de Chicago, [richard.thaler@chicagobooth.edu]. 


\section{Economía del comportamiento: pasado, presente y futuro}

Resumen. La "economía del comportamiento" intenta incorporar ideas de otras ciencias sociales, en especial de la psicología, para enriquecer el modelo estándar. El interés en la psicología del comportamiento humano es un retorno de la economía a sus orígenes. Adam Smith aludió a conceptos clave como la aversión a la pérdida, el exceso de confianza y el autocontrol. La economía del comportamiento encontró resistencia entre economistas que preferían mantener el modelo neoclásico estándar y argumentaban que la psicología se podía ignorar. Este ensayo muestra que esos argumentos han sido rechazados teórica y empíricamente, y que se deber seguir adelante. El nuevo enfoque debería incluir dos tipos de teorías: modelos normativos que caractericen la solución óptima de problemas específicos y modelos descriptivos que capten el comportamiento humano real. Estos últimos incorporarán variables llamadas factores supuestamente irrelevantes, que ayudarán a mejorar el poder explicativo de los modelos económicos.

Palabras clave: economía del comportamiento, comportamiento humano, modelos normativos, modelos descriptivos, factores supuestamente irrelevantes; JEL: A12, B29, D91

\section{Behavioral economics: Past, present, and future}

Abstract. "Behavioral economics" attempts to incorporate insights from other social sciences, especially psychology, in order to enrich the standard economic model. The interest in the psychology of human behavior returns economics to its earliest roots. Adam Smith talked about such key concepts as loss aversion, overconfidence, and self-control. Nevertheless, the modern version of behavioral economics introduced in the 1980 s met with resistance by some economists, who preferred to retain the standard neo-classical model. They introduced several arguments for why psychology could safely be ignored. In this essay I show that these arguments have been rejected, both theoretically and empirically, so it is time to move on. The new approach should include two different kinds of theories: normative models that characterize the optimal solution to specific problems and descriptive models that capture how humans actually behave. The latter theories will incorporate some variables I call supposedly irrelevant factors, which can improve the explanatory power of economic models.

Keywords: behavioral economics, human behavior, normative models, descriptive models, supposedly irrelevant factors; JEL: A12, B29, D91

\section{Economia do comportamento: passado, presente e futuro}

Resumo. A "economia do comportamento" tenta incorporar ideias de outras ciências sociais, especialmente da psicologia, para enriquecer o modelo padrão. $O$ interesse pela psicologia do comportamento humano é um retorno da economia a suas origens. Adam Smith mencionou conceitos-chaves como a aversão à perda, o excesso de confiança e o autocontrole. A economia do comportamento encontrou resistência entre economistas que preferiam manter o modelo neoclássico padrão e argumentavam que a psicologia podia ser ignorada. Este artigo mostra que esses argumentos foram rejeitados teórica e empiricamente e que se deve seguir em frente. O novo enfoque deveria incluir dois tipos de teorias: modelos normativos que caracterizem a solução ideal a problemas específicos e modelos descritivos que captem o comportamento humano real. Estes últimos incorporarão variáveis chamadas fatores supostamente irrelevantes, que ajudarão a melhorar o poder explicativo dos modelos econômicos.

Palavras-chaves: economia do comportamento, comportamento humano, modelos normativos, modelos descritivos, fatores supostamente irrelevantes; JEL: A12, B29, D91 
耳 $\mathrm{n}$ los últimos años ha crecido el interés en la combinación de Dsicología y economía que se ha llegado a conocer como "economía del comportamiento". Como sucede con muchas historias de aparente éxito inmediato, esta se gestó desde hace tiempo. Mi primer artículo sobre el tema se publicó en 1980, siguiendo de cerca el célebre trabajo de Kahneman y Tversky (1979) sobre teoría prospectiva, y hubo precursores anteriores, en especial Simon $(1955$; 1957) y Katona $(1951 ; 1953)$.

El ascenso de la economía del comportamiento a veces se caracteriza como una especie de revolución del paradigma de la economía, pero creo que esa es una mala interpretación de la historia del pensamiento económico. Sería más exacto decir que el método de la economía del comportamiento devuelve el pensamiento económico a la forma en que empezó, con Adam Smith, y continuó en la época de Irving Fisher y John Maynard Keynes en la década de 1930.

A pesar de esta antigua tradición en el campo, el enfoque de la economía basado en el comportamiento tuvo mucha resistencia en la profesión hasta poco. Comienzo este ensayo documentando algunos de los precedentes históricos para utilizar una descripción psicológicamente realista del agente representativo. Luego discuto los argumentos que se han expuesto para mantener el modelo idealizado de homo ceconomicus incluso en contra de la evidencia aparentemente contradictoria. Sostengo que esos argumentos han sido refutados, teórica y empíricamente, incluso en el ámbito en el que se podría esperar que abunde la racionalidad: los mercados financieros. Como tal, es hora de pasar a un enfoque más constructivo.

En el dominio teórico, el problema básico es que nos basamos en una teoría para lograr dos objetivos muy diferentes: caracterizar el comportamiento óptimo y predecir el comportamiento real. No debemos abandonar el primer tipo de teorías pues son elementos esenciales para cualquier tipo de análisis económico, pero debemos añadirles teorías descriptivas adicionales que se deriven de datos y no de axiomas.

En cuanto al trabajo empírico, el enfoque del comportamiento ofrece la oportunidad de desarrollar mejores modelos del comportamiento económico incorporando ideas de otras disciplinas de la ciencia social. Para ilustrar este enfoque más constructivo, me centro en una predicción fuerte del modelo tradicional: que hay un conjunto de factores que no tendrán ningún efecto en el comportamiento económico. Me refiero a ellos como factores supuestamente irrelevantes o FSI. En contra de las predicciones de la teoría tradicional, los FSI 
son importantes; de hecho, en algunas situaciones el determinante más importante del comportamiento es un FSI. Por último, miro al futuro. Alerta de aguafiestas: predigo que la economía del comportamiento eventualmente desaparecerá.

\section{ORÍGENES HISTÓRICOS DE LA ECONOMÍA DEL COMPORTAMIENTO}

Como señaló Simon (1987, p. 612), la expresión "economía del comportamiento" es un tanto extraña. "La expresión 'economía del comportamiento' parece ser un pleonasmo. ¿Qué economía 'no comportamental' podemos contrastar con ella? La respuesta a esta pregunta se encuentra en los supuestos específicos sobre el comportamiento humano que adopta la teoría económica neoclásica". Todos los estudiantes de teoría económica conocen estos supuestos: 1) los agentes tienen preferencias bien definidas y expectativas $y$ creencias no sesgadas; 2) toman decisiones óptimas con base en esas creencias y preferencias. Esto implica, a su vez, que los agentes tienen capacidades cognitivas infinitas (o, dicho de otro modo, que son tan inteligentes como el economista más inteligente) y una fuerza de voluntad infinita, pues eligen lo mejor y no lo que es tentador en el momento; 3) aunque pueden actuar en forma altruista, en especial con amigos y familiares cercanos, su principal motivación es el interés propio. Estos supuestos son los que definen el homo ceconomicus, o como me gusta llamarlo: Econo. La economía del comportamiento simplemente remplaza los Econos por homo sapiens, también conocidos como Humanos.

Para muchos economistas, estos supuestos, junto con el concepto de "equilibrio", definen su disciplina; es decir, estudian Econos en una economía abstracta en vez de Humanos en una economía real. Pero eso no fue siempre así. En efecto, Ashraf, Camerer y Loewenstein (2005) documentan en forma convincente que Adam Smith, a quien se suele considerar el fundador de la economía como disciplina, era un economista del comportamiento bona fide. Consideremos solo tres de los conceptos más importantes de la economía del comportamiento: exceso de confianza, aversión a la pérdida y autocontrol. Sobre el exceso de confianza, Smith (1776, p. 1) aludió a "la petulante presunción que la mayoría de los hombres tiene de sus propias capacidades", que los lleva a sobrestimar sus posibilidades de éxito. Sobre el concepto de aversión a la pérdida, Smith (1759, pp. 176-177) señaló que "el dolor es, en la mayoría de los casos, una sensación más punzante que el placer opuesto y correspondiente". En cuanto al autocontrol, que ahora 
llamamos "sesgo del presente", Smith (1759, p. 273) dijo lo siguiente: "El placer que disfrutaremos dentro de diez años nos interesa muy poco en comparación con el que podemos disfrutar hoy". A George Stigler le gustaba decir que no había nada nuevo en economía, que todo lo había dicho Adam Smith. Resulta que también era cierto para la economía del comportamiento.

Pero Adam Smith estuvo lejos de ser el único de los primeros economistas que tuvo buenas intuiciones sobre el comportamiento humano. Muchos de los que le siguieron compartieron sus puntos de vista sobre el descuento temporal. Por ejemplo, es famosa la siguiente afirmación de Pigou: "Nuestra facultad telescópica es defectuosa y [...] por ello vemos los placeres futuros, por decirlo así, en una escala disminuida" (1920, p. 21). De manera similar, Fisher, quien expuso la primera teoría económica moderna de la elección intertemporal, no pensaba que fuera una buena descripción del comportamiento. Ofreció muchas historias pintorescas para respaldar ese escepticismo: "Así lo ilustra la historia del agricultor que nunca reparaba las goteras de su techo. ¡Cuando llovía, no podía detener las filtraciones, y cuando no llovía, no había filtraciones que detener!” (1930, p. 82). En la Teoría general Keynes anticipó mucho de lo que hoy se llama finanzas del comportamiento. Observó, por ejemplo, que "las fluctuaciones diarias de las ganancias de inversiones existentes, que obviamente son de carácter efímero y poco significativo, tienden a ejercer una influencia excesiva e incluso absurda en el mercado" (1936, p. 154).

Muchos economistas pensaron incluso que la psicología (entonces aún en su infancia) debía desempeñar un papel importante en la economía. Pareto señaló: "El fundamento de la economía política $y$, en general, de toda ciencia social es evidentemente la psicología. Quizá llegue el día en que podamos decidir las leyes de la ciencia social a partir de los principios de la psicología” (1906, p. 21). John Maurice Clark, hijo de John Bates Clark, fue más allá: "El economista puede tratar de ignorar la psicología, pero le es imposible ignorar la naturaleza humana. Si el economista toma prestada del psicólogo su concepción del hombre, su trabajo constructivo puede tener la posibilidad de mantener su carácter puramente económico. Pero si no la toma, no por ello evitará la psicología. Y se verá forzado a elaborar la suya, y será mala psicología” (1918, p. 4).

Clark escribió esas palabras hace casi 100 años, pero aún son válidas, y los economistas del comportamiento han seguido su consejo: tomar en préstamo buena psicología en vez de inventar mala psico- 
logía. ¿Por qué esta sugerencia de sentido común no obtuvo mucha atención durante tanto tiempo?

\section{EXPLICACIONES ELUSIVAS}

En el proceso de hacer más matemáticamente rigurosa a la economía, después de la Segunda Guerra Mundial, parece que la profesión económica perdió su buena intuición sobre el comportamiento humano. Las facultades telescópicas defectuosas fueron remplazadas por un descuento temporal exponencial consistente. Las presunciones petulantes fueron remplazadas por las expectativas racionales. Y los cambios efímeros de los espíritus animales fueron remplazados por la hipótesis del mercado eficiente. En los textos de economía desparecieron los Humanos. ¿Cómo ocurrió eso?

Creo que la explicación más plausible es que los modelos de comportamiento racional se volvieron estándar porque eran los más fáciles de resolver. Esta conjetura no significa menosprecio. Se empieza a aprender física estudiando el comportamiento de los objetos en el vacío; la atmósfera se puede añadir después. Pero los físicos nunca negaron la existencia ni la importancia del aire; en vez de ello trabajaron más duro y construyeron modelos más complicados. Durante muchos años, los economistas reaccionaron a las preguntas sobre el realismo del modelo básico haciendo algo equivalente a negar la existencia del aire, o diciendo que no importaba mucho. A estas reacciones defensivas Matthew Rabin las llama "explicaciones elusivas" (explainawaytions) ${ }^{1}$.

Seamos francos. E1 modelo de comportamiento humano basado en la premisa de que las personas optimizan es y siempre ha sido inverosímil. Por una parte, no toma en cuenta el grado de dificultad del problema que se supone que los agentes están "resolviendo". Consideremos dos juegos: el tres en raya y el ajedrez. Un alumno de primer grado razonablemente capaz puede aprender a jugar la estrategia óptima del tres en raya, y así un modelo que supone que los jugadores eligen en forma óptima en este juego será una buena aproximación del comportamiento real de niños capaces y adultos sobrios. El ajedrez, por su parte, es bastante diferente. La mayoría de nosotros jugamos muy mal al ajedrez y no tenemos posibilidad de ganarle a un programa gratuito de nuestro celular, y mucho menos a un gran maestro. Por tanto, carece de sentido suponer que el agente

${ }^{1}$ Por favor, dirijan todas las quejas por este término directamente a Matthew. 
representativo juega al ajedrez tan bien como al tres en raya. Pero eso es en esencia lo que suponemos en economía.

Cuando suponemos que los agentes maximizan la utilidad (o las ganancias) no condicionamos ese supuesto a la dificultad de la tarea. Suponemos que las personas son igualmente aptas para decidir cuántos huevos comprar para el desayuno que para determinar la cantidad correcta de ahorro para la pensión. Ese supuesto es, a primera vista, absurdo. ¿Por qué se ha mantenido? Se ha aducido un sinnúmero de explicaciones elusivas.

\section{COMO SI}

Dentro de la profesión hubo quejas por la "revolución marginalista" en la década de 1940, y esta revista publicó varios artículos que debatían sobre el realismo de la teoría de que las firmas determinan la producción y contratan trabajadores calculando el punto en el que el costo marginal es igual al ingreso marginal. Uno de los participantes en ese debate fue Richard Lester, de Princeton, quien tuvo la temeridad de preguntar a los propietarios de empresas de negocios cómo tomaban realmente esas decisiones. Cualquier cosa que fuese lo que hicieran las firmas no era captada por la expresión "iguales en el margen”, y Lester terminó así su artículo: "Este artículo plantea graves dudas sobre la validez de la teoría marginal convencional y los supuestos en que se basa" (1946, p. 81). Machlup (1946) asumió la defensa de la teoría tradicional y argumentó que aunque los propietarios de las firmas no supieran calcular los costos e ingresos marginales, tomarían decisiones bastante aproximadas a tales decisiones usando su intuición.

La defensa de Machlup fue refinada y pulida por Friedman (1953, p. 21) en su famoso ensayo "La metodología de la economía positiva". Friedman eludió las preguntas sobre el realismo de los supuestos y argumentó que las teorías se debían juzgar con base en su capacidad para predecir el comportamiento. Propuso lo que hoy es una conocida analogía sobre un billarista experto:

pueden obtenerse excelentes predicciones a partir de la hipótesis de que el billarista taca como si conociera las complicadas fórmulas matemáticas que dan la dirección óptima a las bolas y pudiera estimar a simple vista los ángulos, etc., y al describir la ubicación de las bolas pudiera hacer cálculos fulminantes a partir de las fórmulas, y luego hacer que las bolas vayan en la dirección indicada por las fórmulas. Nuestra confianza en esta hipótesis no se basa en la creencia de que los billaristas, aun los expertos, puedan seguir o sigan el proceso descrito; se deduce más bien de la creencia en que, salvo que de una manera $u$ otra fueran capaces de llegar esencialmente al mismo resultado, no serían billaristas expertos. 
Friedman tenía una reputación bien merecida como comunicador y polemista brillante, y mostró esas habilidades en este pasaje. Usando la expresión formada por dos palabras, "como si", puso fin al debate sobre el realismo de los supuestos en economía. Pero si se examina con cuidado, podemos ver que este pasaje es mera prestidigitación verbal. Primero que todo, no es accidental que Friedman eligiera discutir sobre un billarista experto. En muchas actividades, el comportamiento de un experto puede ser bien captado por un modelo que supone un comportamiento óptimo. ¿Pero qué sucede con los no expertos? ¿No se supone que la teoría económica es una teoría del comportamiento de todos los agentes económicos y no solo de los expertos? La hipótesis del ciclo de vida pretende ser una teoría de cómo ahorra para la pensión el típico ciudadano, no solo quienes tienen maestría en administración de empresas.

Hay otro problema en la defensa de Friedman: incluso los expertos son incapaces de optimizar cuando los problemas son difíciles. Para ilustrarlo, volvamos al juego de ajedrez. Puesto que el ajedrez no tiene elementos estocásticos, desde hace mucho tiempo se sabe que si ambos jugadores optimizan, uno de ellos (el que juegue primero o el otro) debe tener una estrategia ganadora, o ninguno de ellos jugará y la partida terminará en tablas. Pero a diferencia del juego de damas, que ha sido "resuelto" (si ambos jugadores optimizan el juego llega a un empate), las partidas de ajedrez no producen resultados previsibles, incluso entre grandes maestros. A veces ganan las blancas (el primer jugador), las negras ganan con menos frecuencia, y hay muchas tablas. Esto prueba que aun los mejores ajedrecistas del mundo no maximizan. Por supuesto, se puede argumentar que el ajedrez es un juego difícil, lo que es cierto. Pero muchas decisiones económicas también son difíciles.

Una segunda línea de defensa es admitir que no todos hacemos todo como expertos pero argumentar que, si nuestros errores se distribuyen aleatoriamente con media 0 , se eliminarán en el agregado, de modo que en promedio las predicciones del modelo no son sesgadas. Esta fue la reacción usual a la sugerencia de Simon (1955) de que las personas son "satisfactoras" (que buscan a tientas una solución satisfactoria en vez de resolver una solución óptima). Si las elecciones de un satisfactor no difieren sistemáticamente de las de un optimizador, los modelos llevan a predicciones en promedio idénticas (aunque los satisfactores tendrán más ruido). Esta argumentación fue refutada por la obra inicial de Daniel Kahneman y Amos Tversky en la década de 1970.

En una brillante serie de experimentos sobre lo que los psicólogos llaman "juicio" y que los economistas podrían llamar "expectativas" 
o "creencias", Tversky y Kahneman (1974) demostraron que los humanos hacen juicios sistemáticamente sesgados. Y, además, que esos errores eran predecibles con base en una teoría de la cognición humana. La hipótesis de Kahneman y Tversky era que las personas suelen hacer juicios usando una especie de regla general o heurística. Un ejemplo es la "heurística de disponibilidad", por la cual las personas estiman la frecuencia de un hecho mediante la facilidad con la que pueden recordar casos de ese hecho. E1 uso de esta heurística es perfectamente razonable porque la frecuencia y la facilidad de recordar en general se correlacionan positivamente. Sin embargo, el uso de la heurística llevará a errores predecibles cuando la frecuencia y la facilidad de recordar divergen. Por ejemplo, cuando se les pide que estimen la proporción de homicidios y suicidios con armas de fuego en Estados Unidos, la mayoría de las personas piensa que los homicidios con armas de fuego son más comunes, mientras que en realidad los suicidios con armas de fuego son casi el doble. Estas son expectativas que no están cerca de ser "como si” fuesen racionales son predeciblemente sesgadas.

La segunda línea de investigación influyente de Kahneman y Tversky era la toma de decisiones. En particular, en 1979 publicaron su artículo sobre teoría de la prospección, que propuso un modelo "descriptivo" (o lo que Milton Friedman habría llamado "positivo") de la toma de decisiones bajo incertidumbre. La teoría prospectiva pretendía ser una alternativa descriptiva a la teoría de la utilidad esperada de Von Neumann y Morgenstern (1947), que la mayoría de economistas consideran correctamente como una teoría sobre cómo debería tomar decisiones riesgosas un agente racional. La investigación de Kahneman y Tversky documentó numerosas decisiones que violan cualquier definición sensata de racional. El siguiente par de problemas planteados a diferentes grupos de sujetos es una buena ilustración.

\section{Problema 1}

Imagine que enfrenta el siguiente par de decisiones simultáneas.

Primero examínelas y luego indique las opciones que prefiere.

Decisión (1)

Elija entre:
A. Una ganancia segura de $\$ 240$
B. Una posibilidad del $25 \%$ de ganar $\$ 1.000$
y del $75 \%$ de no ganar o perder nada
Decisión (2)
Elija entre:
C. Una pérdida segura de $\$ 750$

$(84 \%)$ 
D. Una posibilidad del $75 \%$ de perder $\$ 1.000$

y del $25 \%$ de no perder nada

La cifra entre paréntesis indica el porcentaje de sujetos que eligieron esa opción. Observamos un patrón que se presentó con frecuencia: los sujetos eran aversos al riesgo en el campo de las ganancias pero buscaban el riesgo en el de las pérdidas. No es obvio de inmediato que haya algo inquietante en estas elecciones, es decir, hasta que uno estudia el siguiente problema.

Problema 2

Elija entre:

E. Una posibilidad del $25 \%$ de ganar $\$ 240$

y del $75 \%$ de perder $\$ 760$

F. Una posibilidad del $25 \%$ de ganar $\$ 250$

y del $75 \%$ de perder $\$ 750$

La inspección revela que si bien el problema 2 está redactado de manera diferente, sus elecciones son formalmente idénticas a las del problema 1. La diferencia es que se han hecho algunas operaciones aritméticas simples para los sujetos. Una vez se hacen estos cálculos, es claro para cada sujeto que la opción $\mathrm{F}$ domina a la opción $\mathrm{E}, \mathrm{y}$ todos eligen en consecuencia. La dificultad es, por supuesto, que la opción E, que no es elegida por nadie, es una combinación de las opciones A y D, elegidas por una gran mayoría de sujetos, mientras que la opción $\mathrm{F}$, que es elegida por todos, es una combinación de $\mathrm{B}$ y $\mathrm{C}$, opciones muy impopulares en el problema 1. Así, este par de problemas ilustra dos conclusiones embarazosas para los partidarios de la elección racional. Primera, las respuestas de los sujetos dependen de la manera como se presenta o "enmarca" un problema, un comportamiento que es inconsistente con casi todo modelo formal. Segunda, al utilizar un marco inteligente, la mayoría de los sujetos puede ser inducida a elegir un par de opciones dominadas por otro par. De nuevo, este comportamiento no parece ser consistente con la idea de que las personas eligen como $s i$ fuesen racionales.

\section{EXPERIMENTOS, INCENTIVOS Y APRENDIZAJE}

En la década de 1980 surgió una segunda clase de explicaciones elusivas, en parte como reacción a los hallazgos de Kahneman y Tversky y a mi primer artículo (Thaler, 1980). Esas réplicas, usualmente expuestas verbalmente en talleres y presentaciones de conferencias y no impresas ${ }^{2}$, pretendían justificar que todo siguiera igual. Algunas críticas se dirigían contra los métodos empíricos usados en esos pri-

2 Sin embargo, para algunas versiones escritas, ver los artículos de Hogarth y Reder (1986; 1987). 
meros artículos, a saber, contra las preguntas de la encuesta hipotética de los problemas 1 y 2 . Los economistas nunca se han sentido muy impresionados por esos datos porque los sujetos nada tienen que perder. Además, normalmente estas preguntas solo se hacían una vez, y muchos argumentaron que no eran una buena indicación de lo que harían las personas en situaciones de la vida real en las que tenían la oportunidad de aprender de errores anteriores. De modo que la crítica tenía dos elementos. Primero, si se aumentan las apuestas, las personas tomarán las preguntas más en serio y elegirán de manera más consistente con la optimización. Segunda, si se les da la oportunidad de aprender, elegirán bien. A menudo la misma persona hacía ambas críticas, pensando que se reforzaban entre sí.

Por supuesto, no hay duda de que la capacidad de practicar mejora el desempeño en la mayoría de las tareas. Nadie juega bien en su primera partida de ajedrez o, a ese respecto, de billar. Y la mayoría de las personas al final llegan a ser al menos competentes en tareas muy complejas, como montar en bicicleta o correr escaleras abajo. De manera similar, la noción de que las personas prestarán más atención cuando las apuestas aumentan es intuitivamente atractiva. Es cierto que prestamos más atención cuando compramos un automóvil que cuando decidimos qué pedir para el almuerzo. Pero en vez de que esos dos argumentos operen juntos, en realidad van en direcciones opuestas. La razón para ello es que, como regla general, cuanto más altas son las apuestas menos a menudo logramos hacer algo.

Consideremos la siguiente lista de actividades económicas: decidir cuánta leche comprar en la tienda, elegir un suéter, comprar un auto, comprar una casa, elegir una carrera, escoger un cónyuge, ahorrar para la pensión. La mayoría de los hogares logran dominar el arte de administrar el inventario de leche mediante prueba y error. Compran demasiada y se echa a perder, compran muy poca y tienen que ir de nuevo a la tienda. Pero si los hogares hacen eso dos veces por semana (para poner un ejemplo), al final lo resuelven, al menos hasta que los hijos se van de casa o prefieren la cerveza. Pocos de nosotros compramos autos con la suficiente frecuencia para ser muy buenos en eso, y las decisiones realmente importantes, como la carrera, el matrimonio y el ahorro para la pensión, dan muy poco espacio para aprender. De modo que los críticos no pueden contar con ambas opciones: en el mundo real las apuestas suelen ser altas o hay innumerables oportunidades para aprender, pero no ambas.

Incluso en los ámbitos donde hay numerosas oportunidades para aprender, las personas no pueden sacar lo mejor en esas situaciones. 
Hace años Daniel Kahneman y yo hicimos un experimento que ilustra este punto. (Nunca publicamos los resultados, de modo que los detalles serán incompletos.) A los sujetos se les dieron formularios parecidos a este:

Caras: $12345 \ldots 181920$

Cruces: $12345 \ldots 181920$

Luego se les mostraron dos sobres de manila etiquetados Caras y Cruces, y se les mostró que cada sobre contenía 20 fichas de póker numeradas del 1 al 20. El experimentador dijo que primero lanzaría una moneda y luego, según el resultado, elegiría una ficha del sobre respectivo. A los sujetos se les permitió marcar cinco números de su formulario, dividiendo sus elecciones como desearan entre las filas de caras y cruces. Cuando el experimentador elegía una ficha y anunciaba el resultado, por ejemplo "Caras, 17 ", cualquier sujeto que hubiera marcado la moneda y el número ganadores recibía algún dinero. Específicamente, si la ficha provenía del sobre Caras, los ganadores recibirían $\$ 2$, pero si la ficha provenía del sobre Cruces ganarían $\$ 3$.

Por supuesto, la estrategia óptima en este juego es marcar únicamente números de la fila Cruces porque tienen un pago esperado 50\% mayor, pero esta estrategia no era obvia para todos. Casi la mitad de los sujetos (estudiantes de maestría en Administración de Empresas en una universidad de alto nivel) adoptó la estrategia correcta de marcar cruces únicamente, pero el resto usó lo que podemos llamar una "estrategia mixta inepta": dividió sus elecciones entre caras y cruces, y la distribución más común fue de tres cruces y dos caras, que coincidía con la relación entre pagos ${ }^{3}$.

El asunto que más nos interesaba a Kahneman y a mí no era, sin embargo, el de estas elecciones iniciales. Era un experimento sobre el aprendizaje. De modo que hicimos que los sujetos repitieran la tarea nueve veces más. Cada vez que se les daba retroalimentación sobre el resultado del lanzamiento de la moneda y del número, a los que adivinaban se les pagaba en efectivo inmediatamente a la vista de los demás sujetos. Intenten adivinar los resultados como experimento mental.

De los sujetos que no imaginaron inmediatamente la estrategia de "todas cruces", ¿cuántos aprendieron a usar esa estrategia durante

${ }^{3}$ Del mismo modo, cuando las caras y las cruces no son igualmente probables, las personas tienden a manifestar un comportamiento de "ajuste de probabilidades" en vez de elegir simplemente el resultado más probable cada vez. Para una encuesta a economistas, ver Vulkan (2000).

Revista de Economía Institucional, vol. 20, n. ${ }^{\circ} 38$, Primer semestre/2oi 8, pp. 9-43 
las nueve pruebas adicionales? La respuesta es 1 . Un sujeto pasó en algún momento a la estrategia de todas cruces, pero fue compensado por otro sujeto que solo había marcado cruces en la primera prueba, y luego pasó a la estrategia mixta inepta en algún momento de la fase de "aprendizaje".

Es instructivo considerar por qué no hubo en esencia aprendizaje en este experimento. A partir de la psicología sabemos que existe aprendizaje cuando hay retroalimentación útil inmediata. Cuando aprendemos a conducir vemos rápidamente cuánta presión ejercemos sobre el acelerador y el freno para arrancar y parar suavemente. Pero en el experimento, a los sujetos primero se les dijo el resultado del lanzamiento de la moneda y luego el número extraído. Casi la mitad de las veces la moneda cayó cara, y los que incluían caras en su portafolio se sentían contentos por seguir en el juego (así solo fuese durante unos segundos). Además, cada vez que alguien ganaba algún dinero con un resultado caras, había un refuerzo para seguir incluyendo algo de esa "estrategia" en el portafolio.

La cuestión general es que el aprendizaje puede ser difícil incluso en un ambiente muy simple. Quienes dictan un curso de introducción a la economía saben que muchos de los primeros principios que son básicos para los modelos de elección racional (como la noción de costos de oportunidad) no son en absoluto intuitivamente obvios para los estudiantes. Pero nuestros modelos suponen que pueden entender conceptos mucho más difíciles, como la inducción hacia atrás.

En lo que respecta al argumento de que a las personas les irá mejor en tareas experimentales si se aumentan las apuestas, hay poca o ninguna evidencia que apoye esa hipótesis. La primera prueba empírica de esa idea fue realizada por David Grether y Charles Plott (1979) en el contexto de una investigación sobre el "fenómeno de la reversión de preferencias", descubierto por los psicólogos Sarah Lichtenstein y Paul Slovic (1971). Lichtenstein y Slovic presentaron a los sujetos dos juegos, uno casi seguro, que llamaron p-bet (por la alta probabilidad), con una posibilidad de 35 a 36 de ganar \$10; el otro, más riesgoso, llamado $\$$-bet, con una posibilidad de 11 a 36 de ganar $\$ 30$, es decir, con un pago potencial mayor. A los sujetos se les pidió que valoraran cada apuesta mencionando el precio más bajo al que la venderían si la poseyeran y, además, que eligieran cuál de las apuestas preferirían tener. El término "reversión de preferencias" surgió del hecho de que entre quienes prefirieron p-bet la mayoría reportó un mayor precio de venta para $\$$-bet, lo que implica que lo valoraban más que a $\mathrm{p}$-bet. 
Grether y Plott (1979) quedaron perplejos por este resultado y decidieron determinar qué error habían cometido los psicólogos para obtener un resultado tan obviamente erróneo. Puesto que el estudio original se basó en preguntas hipotéticas, una de las hipótesis que Grether y Plott examinaron fue si la reversión de preferencias desaparecía cuando las apuestas se hacían con dinero real. (Favorecían esta hipótesis pese a que Lichtenstein y Slovic (1973) ya habían replicado sus resultados con dinero real en un casino de Las Vegas.) Lo que encontraron los sorprendió. El aumento de las apuestas tuvo el efecto deseado de inducir a los sujetos a prestar más atención a sus elecciones (así se redujo el ruido), pero la reversión de preferencias no desapareció; en cambio, ¡su frecuencia aumentó! En los casi 40 años transcurridos desde la publicación del artículo de Grether y Plott no sé de ningún hallazgo de "errores cognitivos" descubiertos y reproducidos con preguntas hipotéticas que desaparecieran cuando se introducían apuestas significativas.

\section{LA SEÑA INVISIBLE DE LA MANO}

Hay una variación de la historia "si hay suficiente dinero en juego las personas se comportarán como Econos" un tanto más complicada. En esta versión, los mercados remplazan el papel esclarecedor del dinero. La idea es que cuando los agentes interactúan en un ambiente de mercado, cualquier tendencia a comportarse mal será superada. Denomino "seña invisible de la mano" a este argumento porque hay una vaga alusión a Adam Smith incrustada en alguna parte, y afirmo que es imposible completar el argumento manteniendo quietas ambas manos.

Supongamos, por ejemplo, que Homero cae presa de la "falacia del costo irrecuperable" y siempre se come todo lo que pone en su plato para cenar, porque no le gusta desperdiciar dinero. Alguien que haga señas invisibles con la mano podría decir, muy bien, puede hacerlo en casa, pero cuando Homero participe en el mercado, ese mal comportamiento será eliminado. Lo que suscita la pregunta: ¿cómo ocurre eso exactamente? Si Homero va a un restaurante y se come todo el rico postre "porque pagó por él", todo lo que ocurre es que engorda un poquito. La competencia no resuelve el problema porque no hay un mercado de restaurantes que retiren rápidamente la comida de los clientes tan pronto han ingerido más de $x$ calorías.

De hecho, pensar que los mercados erradicarán el comportamiento aberrante muestra una falla en la comprensión de cómo funcionan los mercados. Consideremos dos estrategias posibles que las firmas 
podrían adoptar frente a los consumidores que cometen errores. Podrían intentar enseñarles acerca de los costos de sus errores o podrían idear una estrategia para explotar el error y obtener mayores ganancias. Esta última estrategia casi siempre será más rentable. Como regla, es más fácil alcahuetear los prejuicios que erradicarlos. DellaVigna y Malmendier (2006) dan un ejemplo instructivo en su artículo "Pagar para no ir al gimnasio". Ellos estudian el uso que dan los clientes a tres gimnasios que ofrecen a los miembros la opción de pagar $\$ 70$ al mes por uso ilimitado o $\$ 100$ por un paquete de 10 boletas de entrada. Encuentran que los miembros que pagan la tarifa mensual van al gimnasio un promedio de 4,3 veces al mes, con un costo promedio de más de $\$ 17$ por visita.

Obviamente, los miembros mensuales típicos tienen a disposición una oportunidad de arbitraje. ¿Por qué pagar $\$ 17$ por visita cuando podrían pagar $\$ 10$ ? Una posible explicación de este comportamiento es que los clientes entienden que se ven afectados por los costos irrecuperables (sepan o no que es una falacia) y que usan estratégicamente la tarifa de socio como mecanismo de compromiso (bastante ineficaz) para inducir un uso más frecuente del gimnasio. Supongamos que esta explicación es correcta. ¿Qué podría hacer un gimnasio competidor para ganar más dinero y reducir o eliminar el comportamiento poco racional de sus clientes? No sería una gran estrategia explicarles que podrían ahorrar mucho dinero pasando al paquete de 10 boletas. El gimnasio no solo perdería dinero por visita, sino que también renunciaría al pago de los usuarios poco frecuentes que pospondrían el abandono. La persona promedio que abandona no ha ido al gimnasio en 2,3 meses. De modo que si los gimnasios competidores no pueden ganar dinero convirtiéndolos en Econos, ¿quién puede? Supongo que DellaVigna y Malmendier podrían haber empezado a prestar ese servicio convenciendo a las personas de pagar cada visita, pero creo que tomaron una sabia decisión al elegir como carrera la academia y no la consultoría en finanzas personales.

El mismo análisis se aplica a la crisis financiera reciente. Muchos propietarios de vivienda obtuvieron hipotecas con bajas "tasas variables". Una vez se reajustaron las tasas, algunos descubrieron que no podían pagar sus hipotecas a menos que los precios de la vivienda siguieran subiendo y la refinanciación de la hipoteca siguiera disponible a bajo interés. Los prestamistas hipotecarios que iniciaron dichas hipotecas y vendieron inmediatamente los préstamos para titularizarlos ganaron muchísimo dinero mientras duró, pero la crisis financiera posterior fue dolorosa para casi todos. Supongamos que 
al menos algunos de esos acreedores hipotecarios fueron engañados por locuaces corredores de hipotecas ${ }^{4}$. ¿Cómo resolvería el mercado este problema? Nadie se ha hecho rico convenciendo a la gente de que no haga hipotecas imprudentes.

De manera similar, si las personas no siguen los dictados de la hipótesis del ciclo de vida y no logran ahorrar adecuadamente para la pensión, ¿cómo les ayudará el mercado? Sí, hay firmas que venden fondos mutuos, pero compiten con otras que venden autos veloces, televisores de pantalla gigante y vacaciones exóticas. ¿Quién ganará esa batalla? La conclusión es que no hay una poción mágica de mercado que convierta milagrosamente a los Humanos en Econos; de hecho, es más probable que ocurra lo contrario: que los mercados exacerben los sesgos de comportamiento atendiendo esas preferencias.

La conclusión a la que se debería llegar a partir de esta sección es que las explicaciones elusivas no son una buena excusa para suponer que los agentes se comportarán como si fuesen Econos. En vez de ello debemos seguir el consejo de Milton Friedman y evaluar las teorías con base en la calidad de sus predicciones y, si es necesario, modificar algunas de nuestras teorías.

\section{MERCADOS FINANCIEROS 5}

En una evaluación de la importancia potencial de los agentes poco racionales, un buen lugar para empezar son los mercados financieros. Lo digo porque los mercados financieros tienen las características que harían más difícil encontrar evidencia de mal comportamiento. Estos mercados tienen bajos costos de transacción, apuestas altas, mucha competencia (excepto quizá en algunos sectores bancarios) y, lo que es fundamental, la posibilidad de vender en corto. Las ventas en corto hacen posible que, incluso si la mayoría de los inversionistas son tontos, la actividad de quienes arbitran "dinero inteligente" asegure que los mercados se comporten "como si" todos fueran inteligentes. Este es el sustento intelectual de la hipótesis del mercado eficiente (HME).

Esta hipótesis tiene dos componentes distintos. El primero, al que llamo la disposición de "no hay almuerzo gratis", es que no es posible "ganarle al mercado" sobre una base adecuadamente ajustada al riesgo. Es abundante la literatura dedicada a probar esta hipótesis, con mu-

${ }^{4}$ Por supuesto, algunos prestatarios pueden haber planeado incumplir los pagos y vivir sin pagar alquiler durante el mayor tiempo posible antes de irse. Entonces actuaban como Econos.

${ }^{5}$ Esta sección se basa en Barberis y Thaler (2003). 
chos argumentos de cada lado. La dificultad para evaluar los distintos argumentos es concordar en la manera de calcular el riesgo. Por ejemplo, hay bastante acuerdo en que la estrategia de comprar "acciones de valor", verbigracia, aquellas con baja relación precio-ganancias o valor contable, produce mayores rendimientos que comprar "acciones de crecimiento", que tienen una alta relación precio-ganancias. Pero hay un debate sobre la explicación de esos rendimientos excesivos. Los estudiosos del comportamiento (p. ej., De Bondt y Thaler, 1985, 1987; Lakonishok, Shleifer y Vishny, 1994) argumentan que los rendimientos excesivos reflejan una mala fijación de precios. Por su parte, defensores del mercado eficiente como Fama y Frech (1993) argumentan que las acciones de valor tienen altos rendimientos porque esas acciones son riesgosas. Aunque no sería correcto decir que este argumento se ha definido a satisfacción de todos, creo que nadie ha podido identificar una manera específica en que las acciones de valor son más riesgosas que las acciones de crecimiento (p. ej., las acciones de valor tienden a tener betas más bajas, la medida tradicional del riesgo en el modelo de fijación de precios de los activos de capital). Aun así, mientras los académicos debaten cuál es la interpretación correcta de estos resultados empíricos, sigue siendo cierto un hecho importante documentado por primera vez en la tesis de doctorado de Jensen (1968): en promedio, la activa industria de fondos mutuos no le gana al mercado.

Por tanto, desde el punto de vista de un inversionista, este aspecto de la hipótesis del mercado eficiente se puede considerar con seguridad al menos aproximadamente cierto. Pero es importante no malinterpretar este resultado. El hecho de que los rendimientos del mercado bursátil no sean predecibles no implica que los precios de las acciones sean "correctos". Este es el segundo aspecto de la HME, al que llamo el componente "el precio es correcto". La inferencia de que la imprevisibilidad implica precios racionales es lo que Shiller una vez calificó como "uno de los errores más notables en la historia del pensamiento económico" (1984, p. 459). Es un error porque, así como la trayectoria de un niño que corre en el patio de recreo puede ser del todo impredecible, no es probable que sea el resultado de maximizar una función objetivo bien especificada (aparte de divertirse).

El componente "el precio es correcto" de la HME es, en mi opinión, el más importante de los dos ingredientes de la teoría. Es importante porque si los precios son “incorrectos”, los mercados no están haciendo 
un trabajo eficiente de asignación de recursos ${ }^{6}$. $\mathrm{El}$ problema ha sido presentar una prueba convincente de esta parte de la teoría porque el valor intrínseco de un título normalmente no se puede conocer. Si el precio de Apple Inc. fuese demasiado alto o demasiado bajo, ¿‘cómo lo sabríamos? Resulta que hay clases de activos para los que podemos decir algo definitivo, a saber, aquellos para los cuales podemos usar la ley de un precio único como prueba. Aunque no conozcamos el precio racional de Apple, podemos decir con certeza que los certificados de acciones con números impares (si aún existen) se deberían vender al mismo precio que los de números pares. Exploré algunos de esos ejemplos en mi trabajo con Owen Lamont ${ }^{7}$, y hace poco él me comentó otro que describiré aquí.

Un tipo de título que ha sido una fuente provechosa de pruebas de la ley de un precio único son los fondos mutuos cerrados. A diferencia de sus primos, los fondos mutuos abiertos, que aceptan nuevas inversiones que se valoran según el valor neto de los títulos del fondo, y luego redimen los retiros del mismo modo, los fondos cerrados son, como indica su nombre, cerrados a nuevos inversionistas. Cuando se inicia el fondo, se consigue y se invierte cierta cantidad de dinero, las acciones del fondo luego se cotizan en mercados organizados como la Bolsa de Nueva York. E1 hecho curioso acerca de los fondos cerrados, observado inicialmente por Graham (1949), entre otros autores, es que el precio de las acciones no siempre es igual al valor neto de los activos de los títulos subyacentes. Los fondos suelen venderse con descuentos del 10 al 15\%, pero a veces se venden con primas sustanciales. Esta es la historia de uno de ellos.

El fondo que quiero destacar aquí tiene el símbolo bursátil CUBA. Fundado en 1994, su nombre oficial es Herzfeld Caribbean Basin Fund, que mantiene el 69\% de sus tenencias en acciones de Estados Unidos y el resto en acciones extranjeras, principalmente mexicanas. Se le dio el símbolo "CUBA" a pesar de que no posee títulos cubanos y de que desde 1960 no es legal que una compañía estadounidense haga negocios en Cuba (aunque eso puede cambiar en algún momento). Las disposiciones legales, más el hecho de que no existan títulos negociados en Cuba, significa que el fondo no tiene intereses financieros en el país con el que comparte su nombre. Históricamente, el fondo CUBA cotizaba con un descuento del 10 al 15\% del valor neto de los activos.

${ }^{6}$ Lo que, por supuesto, no significa que otro sistema lo haría mejor.

7 Ver Lamont y Thaler (2003a y 2003b).

Revista de Economía Institucional, vol. 20, n.o 38 , Primer semestre/2oi 8, pp. 9-43 
Gráfica 1

Precio y valor neto de los activos del fondo CUBA

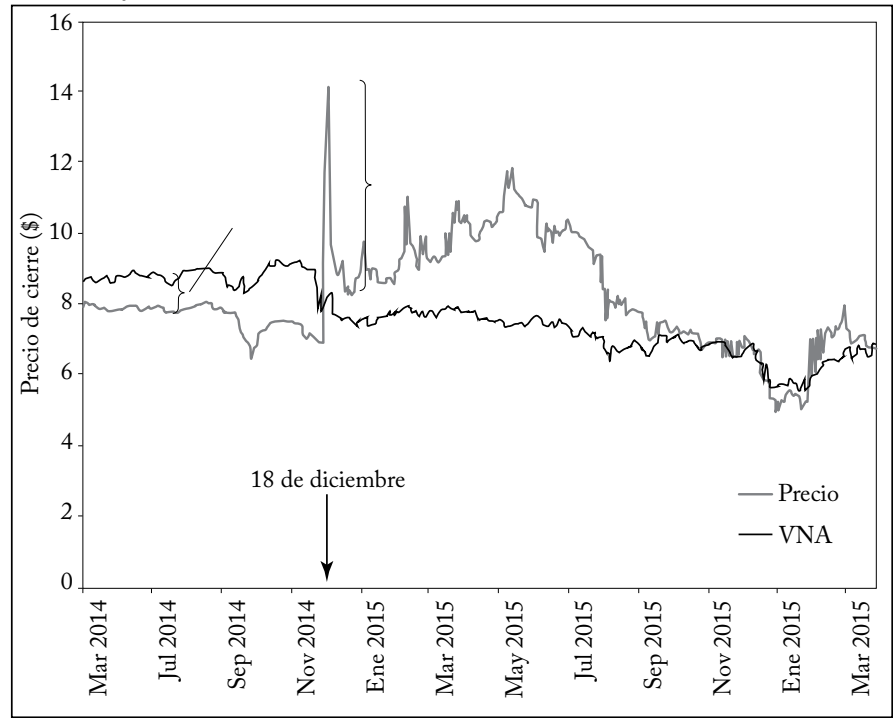

Nota: el 18 de diciembre de 2014, el presidente Obama anunció que iba a levantar algunas restricciones contra Cuba.

Fuente: Bloomberg.

La gráfica 1 representa el precio de la acción y el valor neto de los activos del fondo CUBA durante un periodo que comienza en septiembre de 2014. Podemos ver que durante los primeros meses el precio de la acción estuvo en el rango de descuento normal del 10 al 15\%. Luego algo sucedió abruptamente el 18 de diciembre de 2014. Aunque el valor neto de los activos del fondo apenas se altera, el precio de las acciones saltó a una prima del 70\%. ¡Mientras que antes era posible comprar $\$ 100$ de activos Caribbean por solo $\$ 90$, el día siguiente esos activos costaban $\$ 170$ ! Como los lectores quizá hayan adivinado, este salto del precio coincidió con el anuncio del presidente Obama de su intención de relajar las relaciones diplomáticas de Estados Unidos con Cuba. Aunque el valor de los activos del fondo se mantuvo estable, la prima sustancial duró varios meses, y al final desapareció, casi un año después.

Este ejemplo y otros similares muestran que los precios pueden diferir significativamente del valor intrínseco, incluso cuando el valor intrínseco se mide fácilmente y se reporta cada día. ¿Qué deberíamos pensar entonces sobre índices de mercado más amplios? ¿También pueden saltar de súbito? Es indudable que el alza de las acciones de las empresas de tecnología de finales de la década de 1990 parecía una burbuja en ese momento, pues las acciones se vendían a múltiplos muy altos de las ganancias (o a precios de liquidación las que no tenían 
ganancias), y le siguió una caída de precios de más de dos tercios del índice NASDAQ. Observamos un patrón similar en la disparada de la vivienda a mediados de la década de 2000, especialmente en ciudades como Las Vegas y Phoenix. Los precios divergían notablemente de su tendencia de largo plazo de vender a precios unas 20 veces mayores que el arriendo, solo para retornar a la tendencia de largo plazo. Debido a las diversas formas de apalancamiento, esta alza y esta caída de precios ayudaron a generar la Gran Recesión mundial.

La diferencia entre el ejemplo del fondo CUBA y estas burbujas mucho más grandes es que resulta imposible probar que los precios en estas últimas fueran alguna vez incorrectos. No hay evidencias claras e irrefutables. Pero ciertamente parece que los precios de los activos pueden diferir significativamente del valor fundamental. Quizá deberíamos adoptar la definición de eficiencia de mercado propuesta por Fischer Black en su discurso presidencial a la American Finance Association, que tenía el intrigante título de una sola palabra "Ruido". Black dice allí:

podríamos definir un mercado eficiente como aquel en el que el precio se desvía del valor por un factor de 2 , es decir, cuando el precio es más de la mitad del valor y menos del doble del valor. El factor de 2 es arbitrario, por supuesto. Pero me parece intuitivamente razonable, a la luz de las fuentes de incertidumbre sobre el valor y la intensidad de las fuerzas que tienden a ocasionar que el precio retorne al valor. Según esta definición, creo que casi todos los mercados son eficientes casi todo el tiempo. 'Casi todo' significa al menos el 90\%. (Black, 1986, p. 553)

Se pueden objetar varios aspectos de la definición de Black pero a mi parecer es correcta, y si Black hubiese vivido para ver la burbuja de la empresas de tecnología de los años noventa podría haber revisado su cifra hasta 3. Querría hacer dos comentarios al respecto. El primero es que la hipótesis del mercado eficiente ha sido un concepto muy útil y esencial en la historia de la investigación de los mercados financieros. De hecho, sin la HME no habría habido un punto de referencia con el que comparar resultados anómalos. El único peligro creado por el concepto de la $\mathrm{HME}$ es si las personas, en especial los diseñadores de política, lo consideran cierto. Si estos últimos piensan que las burbujas son imposibles, quizá no tomen las medidas adecuadas para moderarlas. Por ejemplo, creo que habría sido apropiado aumentar los requisitos de los préstamos hipotecarios en ciudades donde la relación precio-alquiler parecía más burbujeante. En cambio, fue un periodo en el que los requisitos de los préstamos fueron inusualmente laxos. 
Debo hacer un comentario más general. Por muchas razones podríamos esperar que los mercados financieros sean los más eficientes de todos los mercados. Son los únicos en los que generalmente es posible vender en corto, una característica esencial si esperamos que los precios sean "correctos". Pero si los mercados financieros pueden desviarse en un factor de 2 , ¿cuánta confianza deberíamos tener en que los precios de otros mercados son buenas medidas del valor, donde no hay posibilidades reales de arbitraje?

Para dar solo un ejemplo, consideremos los mercados de trabajo. En los últimos años se ha prestado mucha atención a la creciente desigualdad del ingreso y de la riqueza en todo el mundo (Piketty, 2014; Atkinson, Piketty y Sáez, 2011). Aunque ha habido mucho debate sobre la causa de esta tendencia, la mayor parte de la discusión en economía se basa en la presunción de que las diferencias de ingreso reflejan diferencias de productividad. ¿Es fundamentada esa presunción? Si los precios de las acciones se pueden desviar en un factor de 2, ¿eso no sería cierto para los trabajadores, desde los que preparan hamburguesas hasta los directores ejecutivos?

Hay razones para el escepticismo acerca de esa presunción desde la parte inferior hasta la parte superior de la escala de ingresos. En el extremo inferior de la distribución de salarios, Slichter (1950) dio inicio a una extensa literatura que documenta extraños diferenciales de salarios entre industrias. En pocas palabras, algunas industrias pagan más que otras, y esto se aplica a los trabajadores administrativos y a los conserjes, así como a los ejecutivos mejor pagados. Los importantes artículos de Krueger y Summers (1988) y Dickens y Katz (1986) reavivaron esta literatura, que se resume en Thaler (1989). Card, Heining y Kline (2013) documentan hallazgos similares en Alemania usando datos de panel que permiten efectos fijos individuales. Encuentran que cuando los trabajadores pasan de una industria que paga el cuartil inferior a una que paga el cuartil superior sus salarios aumentan; y que sucede lo contrario cuando los trabajadores pasan de una industria de altos salarios a una de bajos salarios. Parece inverosímil que estos trabajadores se vuelvan mucho más o mucho menos productivos simplemente cambiando de industria.

En el otro extremo de la escala, la relación entre la paga de un director ejecutivo y la del trabajador promedio se disparó en las últimas décadas. En las grandes empresas con sede en Estados Unidos esta relación era de 20 a 1 en 1965 y de más de 300 a 1 en 2014, más del doble que en cualquier otro país (Mishel y Davis, 2015). Algunos economistas argumentan, por supuesto, que tal aumento simplemente 
refleja la creciente productividad de los directores ejecutivos (p. ej., Kaplan, Klebanov y Sorensen, 2012). Pero, ¿qué tan seguros deberíamos estar de esa apreciación? La paga del director ejecutivo suele ser fijada por el comité de remuneración de la junta directiva, formada por asesores cuyas recomendaciones se basan, en parte, en la paga de otros directores ejecutivos. Este proceso recursivo que se alimenta a sí mismo no suscita mucha confianza en que la paga y el desempeño estén muy correlacionados. Y no hay manera de resolver esta discusión. Solo quiero repetir mi pregunta. Si los precios de las acciones pueden desviarse en un factor de 2, ¿por qué deberíamos estar seguros de que otros mercados no divergen tanto o más?

\section{UNA TEORÍA, DOS TAREAS}

La conclusión a la que llego a partir de la investigación en finanzas del comportamiento es que incluso esos mercados más eficientes a menudo llevan a resultados empíricos inconsistentes con teorías basadas en inversionistas racionales que toman decisiones en mercados con bajos costos de transacción. En otras palabras, los resultados que obtenemos no concuerdan con la hipótesis de que los inversionistas se comportan "como si" fuesen racionales. Y se debería sospechar aún más de que tales modelos hagan buenas predicciones en otros mercados donde el arbitraje es imposible. Por tanto, ¿qué le debería ocurrir a la teoría económica?

El problema es que les pedimos a nuestras teorías que hagan dos tareas diferentes. La primera es encontrar soluciones óptimas a los problemas y la otra describir cómo eligen realmente los Humanos. Por supuesto, en un mundo integrado únicamente por Econos no habría necesidad de dos tipos diferentes de modelos. Los agentes económicos tendrían la cortesía de tomar las decisiones óptimas que el modelo determine que son las mejores (al menos en promedio). Pero estamos muy lejos de ese mundo: nosotros, los Humanos, luchamos por determinar cuál sería la mejor opción y luego para tener suficiente fuerza de voluntad para materializar esa elección, en especial si requiere aplazar la gratificación. De modo que necesitamos teorías económicas descriptivas.

La primera y más exitosa de estas teorías es la prospectiva de Kahneman y Tverksy (1979), que ha tenido enorme impacto en la economía y en la ciencia social en general ${ }^{8}$. Más allá de las ideas del modelo en sí, la teoría prospectiva es una plantilla para la nueva clase

${ }^{8}$ Según Google Académico, el artículo ha sido citado casi 40.000 veces.

Revista de Economía Institucional, vol. 20, N. ${ }^{\circ}$ 38, Primer semestre/2oi 8, pp. 9-43 
de teorías que necesitamos. La teoría de la utilidad esperada sigue siendo el patrón oro con respecto a cómo tomar decisiones frente al riesgo. La teoría prospectiva pretende ser un complemento de la teoría de la utilidad esperada, que nos dice cómo toman realmente las personas tales decisiones. Usar una teoría para ambos propósitos no tiene más sentido que usar un martillo para clavar puntillas y para aplicar pintura.

Algunos economistas podrían pensar que sin optimización no puede haber teoría, pero en un convincente ensayo Arrow rechazó esta idea. "Permítanme descartar un punto de vista que quizá no siempre se haya expresado pero que parece implícito en muchos escritos. Parece afirmar que una teoría de la economía se debe basar en la racionalidad, como cuestión de principios. De lo contrario no puede haber teoría" (1986). Arrow señaló que podía haber muchas teorías formales rigurosas basadas en el comportamiento que los economistas no estarían dispuestos a llamar racional. También señaló la inconsistencia de un teórico económico que se afana durante meses por encontrar la solución óptima de un problema económico complejo y luego supone alegremente que los agentes de su modelo se comportan como si fuesen naturalmente capaces de resolver ese mismo problema. “Tenemos la curiosa situación de que el análisis científico imputa un comportamiento científico a sus sujetos. Esto no es necesariamente una contradicción, pero parece llevar a una regresión infinita”.

Este no es el lugar y no soy la persona para presentar una hoja de ruta detallada de lo que debería ser un enfoque de la teoría económica basado en el comportamiento, pero quizá sean apropiadas algunas breves reflexiones. La primera es que las teorías económicas del comportamiento (o cualquier teoría descriptiva) deben abandonar el razonamiento inductivo que es el núcleo de las teorías neoclásicas y adoptar un enfoque deductivo en el que los supuestos y las hipótesis se basen en observaciones del comportamiento humano. En otras palabras, la teoría económica del comportamiento debe ser una teoría basada en evidencias. La evidencia en la que se pueden basar estas teorías puede provenir de la psicología u otras ciencias sociales o puede ser hecha en casa. Hay quienes pueden preocuparse porque las teorías se basen en la observación empírica, pero esta metodología tiene una rica tradición en la ciencia. La revolución copernicana, que puso al sol en el centro de nuestro sistema solar en vez de la Tierra, se basó en datos del movimiento de los planetas y no en primeros principios.

Una segunda reflexión general es que no deberíamos esperar que surja una nueva gran teoría del comportamiento para sustituir al 
paradigma neoclásico. Ya tenemos una gran teoría y hace un buen trabajo al caracterizar cómo operan los conceptos de elección óptima y de equilibrio. Las teorías del comportamiento se parecerán más a la ingeniería, un conjunto de mejoras prácticas que lleve a mejores predicciones del comportamiento. Hasta ahora, la mayoría de esas mejoras comportamentales se centran en dos temas generales: preferencias y creencias.

\section{PREFERENCIAS DE COMPORTAMIENTO}

La teoría prospectiva es un buen ejemplo de un modelo basado en supuestos sobre preferencias que difieren de los que se usan para derivar la teoría de la utilidad esperada. Específicamente, la mayor parte del poder predictivo de la teoría prospectiva proviene de tres supuestos básicos sobre las preferencias. Primero, la utilidad se deriva de cambios en la riqueza con respecto a algún punto de referencia, y no de los niveles de riqueza, como suelen suponer las teorías basadas en la utilidad esperada ${ }^{9}$. Segundo, la "función de valor" que traduce en utilidad los cambios percibidos en la riqueza se dobla en el origen: se da más peso a las pérdidas que a las ganancias; es decir, "aversión a la pérdida”. Tercero, las ponderaciones de decisión son una función de probabilidades $\Pi(p)$ donde $\Pi(p) \neq p$. Estos aspectos de la teoría se dedujeron del estudio de las decisiones que tomaron los sujetos cuando se les pidió que eligieran entre opciones.

Otras dos ramas de investigación se basan en modelos de preferencias. El primer tema es la elección intertemporal. Como revelan las citas de Smith, Pigou y Fisher antes mencionadas, durante mucho tiempo a los economistas les ha preocupado que las personas muestren lo que hoy llamamos preferencias "sesgadas hacia el presente", lo que significa que la tasa de descuento entre "ahora" y "después" es mucho mayor que entre "después" y "mucho después". Tales preferencias pueden llevar a un comportamiento inconsistente en el tiempo pues esperamos ser pacientes al elegir entre una recom-

\footnotetext{
${ }^{9}$ Es cierto que von Neumann y Morgenstern no especifican cuáles son los argumentos de su función de utilidad, y algunos sostienen que simplemente se podría revisar la utilidad esperada para que sea una función del ingreso y no de la riqueza para incorporar esta característica. Esto olvida que la definición de "ingreso" depende de una teoría de la contabilidad mental para saber en qué horizonte de tiempo se mide el ingreso. Si el "ingreso" es el ingreso de por vida, es lo mismo que la riqueza. Pero si es el ingreso diario se obtienen predicciones muy diferentes. Ver, p. ej., la controvertida literatura sobre la oferta de trabajo del taxista (Camerer et al., 1997; Crawford y Meng, 2011; Farber, 2015).
}

Revista de Economía Institucional, vol. 20, n. ${ }^{\circ} 38$, Primer semestre/2oi 8, pp. 9-43 
pensa más pequeña en un año y una recompensa más grande en un año más una semana, pero cuando pasa el año y la recompensa más pequeña está disponible "ahora", sucumbimos a la tentación. Si las personas advierten que tienen esas preferencias pueden optar por comprometerse ahora a elegir la recompensa aplazada más grande, una estrategia que luego lamentarán (al menos durante más o menos una semana).

Se han propuesto dos tipos de modelos para tratar estas preferencias aberrantes. Uno se basa en un enfoque de dos yoes (o "dos sistemas") que pretende captar el conflicto inherente que define los problemas de autocontrol. En la versión de este tipo de modelo que Hersh Shefrin y yo favorecemos (Thaler y Shefrin, 1981) se supone que los individuos tienen un "planificador" de larga vista y un "hacedor" miope que interactúan en un modelo similar a los modelos de agencia de las organizaciones. Schelling (1984) y Fudenberg y Levine (2006) también propusieron modelos de dos yoes para caracterizar este comportamiento.

Aunque estos modelos de dos yoes proporcionan más textura psicológica, no han sido tan populares entre teóricos económicos como el modelo "beta-delta" más simple y más manejable propuesto originalmente por Strotz (1955) y luego refinado por Laibson (1997) y O'Donoghue y Rabin (1999). En estos modelos, delta es la tasa de descuento exponencial estándar y beta mide la impaciencia a corto plazo. El modelo estándar es solo el caso especial en que beta es 1. E1 modelo beta-delta es un buen ejemplo de lo que Rabin llama EPME, lo que significa "extensiones portátiles de modelos existentes". La facilidad con la que los economistas pueden incorporar tales modelos a un análisis estándar tiene obvio atractivo.

Junto con la elección intertemporal, el aspecto importante de las preferencias que ha recibido mucha atención de los teóricos del comportamiento económico es el de "preferencias con respecto a otros". Todos estos modelos fueron alentados por resultados empíricos que muestran que los humanos no son totalmente egoístas, ni siquiera con desconocidos. Por ejemplo, en juegos del dilema del prisionero de una sola vez, coopera entre el 40 y el $50 \%$ de los sujetos, tanto en experimentos de laboratorio como en entornos de juego donde las apuestas son superiores a $£ 10.000$ (van der Assem, Van Dolder y Thaler, 2012). De manera similar, las personas cooperan en entornos de bienes públicos cuando la estrategia egoísta racional es no dar nada. Los modelos más destacados en este ámbito son los de Rabin (1993) y Fehr y Schmidt (1999). La manera más fácil de resumir esta litera- 
tura es decir que los Humanos son más amables y más corteses que los Econos. Específicamente, su primer instinto es cooperar cuando esperan que otros cooperen.

\section{CREENCIAS DE COMPORTAMIENTO}

Cuando las personas toman decisiones, las toman con base en un conjunto de expectativas sobre las consecuencias de sus decisiones y en los muchos factores exógenos que pueden determinar cómo será el futuro. Los economistas suelen suponer que dichas creencias no son segadas. Aunque la hipótesis de expectativas racionales, formulada por Muth (1961) y desarrollada por Lucas (1976) y muchos otros, a menudo se considera un enfoque específico de la modelación económica, especialmente en macroeconomía, creo que es justo decir que la idea es en esencia convencional. El supuesto de expectativas racionales hace explícita una idea que es un lugar común en teoría económica: que los agentes actúan como si entendieran el modelo (y también las técnicas econométricas más avanzadas). Que este supuesto sea empíricamente válido es otro asunto.

Las pruebas explícitas de expectativas racionales per se son poco comunes porque rara vez observamos u obtenemos como respuesta datos de expectativas reales. Cuando lo conseguimos, a menudo encontramos que las expectativas reales divergen de lo que razonablemente se llamaría racional. Por ejemplo, Case, Shiller y Thompson (2012) encontraron que los propietarios de vivienda durante el periodo de rápido aumento de precios de 2000-2005 esperaban que esos precios siguieran aumentando a tasas de dos dígitos en la década siguiente. Si bien no se puede probar que esas expectativas eran irracionales, sí parecen excesivamente optimistas, tanto ex ante como expost. Además, en este campo y en muchos otros, las expectativas parecen depender demasiado de la extrapolación de las tendencias recientes. Como primera aproximación, las personas esperan que lo que sube seguirá subiendo.

También vemos violaciones de las expectativas racionales en las predicciones de los rendimientos del mercado bursátil realizadas por los directores ejecutivos financieros estudiados por Ben-David, Graham y Harvey (2013). A esos ejecutivos financieros se les pidió que predijeran las tasas de rendimiento a un año del S \& P 500 y dieran límites de confianza del $80 \%$. Como quizá era de esperar, los ejecutivos financieros carecían de la capacidad para predecir los rendimientos del mercado bursátil. Lo que es más inquietante es que no tenían conciencia de su falta de capacidad de predicción. Si tuviesen previsiones bien calibradas, el rendimiento bursátil real estaría entre 
su estimación alta y baja el $80 \%$ del tiempo. En vez de ello, sus rangos incluyeron el resultado en apenas el 36\% de las previsiones registradas durante un periodo de diez años. Esto es muy similar al exceso de confianza observado en decenas de estudios de laboratorio.

E1 exceso de confianza y la extrapolación excesiva son tan solo dos ejemplos de creencias sesgadas que han sido documentadas por psicólogos que estudian el juicio humano. Esta literatura comenzó con las tres heurísticas originales que estudiaron Kahneman y Tversky: disponibilidad, representatividad, y anclaje y ajuste, pero desde entonces se han investigado y documentado muchas otras: sesgo retrospectivo, sesgo de proyección, atención excesiva a la característica del entorno más destacada, etc. Para cada uno de estos sesgos y otros más, los economistas han elaborado modelos descriptivos para intentar que las implicaciones de los sesgos sean más específicas y rigurosas.

El hecho de que haya una larga lista de sesgos es a la vez una bendición y una maldición. La bendición es que hay un sinnúmero de formas interesantes en las que el juicio humano diverge de las expectativas racionales, cada una de las cuales ofrece la posibilidad de proporcionar información útil sobre el comportamiento económico. La maldición es que la longitud de la lista parece ofrecer un número peligrosamente grande de grados de libertad a los teóricos. Aunque no descarto que este último riesgo se desborde, pienso que las buenas prácticas científicas pueden atenuarlo.

Lo que es más importante recordar es que todos estos sesgos tienen respaldo empírico, y muchos de los resultados de laboratorio luego se han replicado en el campo. Ya se ha impuesto entonces alguna disciplina: los economistas del comportamiento pueden recurrir a una larga lista de posibles factores explicativos, pero para cada uno hay al menos alguna evidencia de que el factor es real. Comparemos esto con los grados de libertad disponibles en los modelos tradicionales basados en la racionalidad. Por ejemplo, consideremos el elusivo factor multipropósito: los costos de transacción. En abstracto, dichos costos pueden explicar muchas anomalías, pero salvo que esos costos se puedan medir el uso del concepto es indisciplinado. Si nos limitamos a variables que tienen base empírica, la economía llegará a ser más disciplinada.

Por supuesto, no pretendo sugerir que la teoría económica del comportamiento es un producto terminado. El campo es nuevo y crece rápidamente. Uno de los objetivos debería ser el de idear teorías que no solo sean extensiones portátiles de modelos existentes sino también extensiones comprobables. Dejaré que Rabin decida dónde insertar la letra $\mathrm{C}$ en su acrónimo EPME. 


\section{FACTORES SUPUESTAMENTE IRRELEVANTES}

Es raro que la teoría económica haga predicciones sobre magnitudes. La mayoría de las teorías hacen predicciones sobre el signo de un efecto. Las curvas de demanda se inclinan hacia abajo y las de oferta se inclinan hacia arriba. Cuando un teórico inteligente puede colegir una predicción más precisa a partir de la teoría, las cosas pueden ponerse interesantes. El acertijo de la prima de las acciones es un ejemplo oportuno. La predicción de primer orden de que las acciones son más riesgosas que los bonos y, por tanto, deben tener una tasa de rendimiento más alta es respaldada contundentemente por los datos históricos. Pero Mehra y Prescott (1985) demostraron que el modelo estándar no puede explicar simultáneamente la baja tasa histórica libre de riesgo y una prima a las acciones en las vecindades del 6\%; el mayor valor que pudieron justificar fue del 0,35\%. Este ejercicio de calibración dio lugar a una extensa e interesante literatura.

Aunque tales ejemplos de predicciones sobre la magnitud son poco comunes, la teoría económica hace algunas predicciones bastante precisas sobre el tamaño de los efectos, a saber, de variables que no deberían tener ningún efecto en el comportamiento. Por ejemplo, las siguientes cosas no deberían importar: el encuadre de un problema, el orden de presentación de las opciones, la preponderancia de una opción sobre otra, la presencia de un costo irrecuperable (o una ganancia) anterior, si el cliente de un restaurante puede ver las opciones de postre cuando elige si sigue la dieta planeada, etc. A estas y a un sinnúmero de otras variables posibles que no pueden influir e influyen en las elecciones las llamo "factores supuestamente irrelevantes" o FSI. Una de las maneras más importantes en que la economía del comportamiento puede enriquecer el análisis económico es la de señalar los FSI que más importan.

Un campo en el que mejor se ha documentado la importancia potencial de los FSI es el del ahorro para la pensión. En un modelo estándar del ciclo de vida, los Econos calculan la trayectoria de consumo óptima y luego siguen un plan de ahorro, inversión y eventualmente desahorro que maximiza la utilidad de por vida, incorporando plenamente las probabilidades actuariales correctas de las tasas de mortalidad del esposo y la esposa así como los riesgos de divorcio, enfermedad, etc. Este es un problema que hace parecer fácil jugar al ajedrez como un gran maestro internacional. El ajedrez no tiene incertidumbre ni problemas de autocontrol que arruinen la tarea. No debería sorprender entonces que muchos Humanos tengan problemas para determinar el ahorro para la pensión en un mundo 
de contribución definida en el que deben tomar todas las decisiones por sí mismos. Sin embargo, se ha podido ayudar a las personas en esta intimidante tarea con apoyo de algunos FSI.

El primer FSI que ha sido importante para ayudarles a ahorrar para la pensión es el uso inteligente de la opción predeterminada. En un mundo de Econos, en especial cuando hay mucho en juego como en el caso del ahorro para la pensión, no debería importar si alguien se inscribe en el plan excepto que decida no participar o sea excluido del plan si decide participar. El costo de marcar una casilla y llenar un formulario debe ser muy bajo comparado con los beneficios de recibir una contrapartida y acumulados libres de impuestos durante algunas décadas. No obstante, el paso a la opción predeterminada ha tenido enorme impacto en las tasas de utilización de los planes 401(k).

El primer artículo que documentó este efecto fue el de Madrian y Shea (2001), que usó datos de una compañía que en 1999 adoptó lo que hoy se llama "inscripción automática". Anteriormente, para unirse al plan 401(k) los empleados debían llenar algunos formularios, y si no los llenaban no se inscribían. Madrian y Shea compararon las tasas de inscripción de nuevos empleados bajo el antiguo régimen de "suscripción voluntaria" de 1998 con las de 1999, donde los empleados debían optar por no participar si no quería unirse. Antes de la inscripción automática, solo el $49 \%$ de los empleados se unía al plan durante el primer año de empleo; después del paso a la inscripción automática, el $86 \%$ estaba inscrito en el primer año. ¡Supuestamente irrelevante! Hoy la inscripción automática está muy extendida. Más de la mitad de los grandes empleadores de Estados Unidos usa el concepto y el Reino Unido está poniendo en marcha un plan nacional de ahorros de contribución definida con esta característica. En la mayoría de los planes, incluido el plan nacional del Reino Unido, las tasas de no participación son de un 10\%.

Un problema de la inscripción automática es que muchos planes inicialmente inscriben a los empleados a una tasa de ahorro baja; en Estados Unidos suele ser de solo un 3\% de la paga. Como Madrian y Shea señalaron en su artículo, una tasa de ahorro predeterminada inicial tan baja puede tener la consecuencia indeseada de reducir los ahorros de quienes, sin esa predeterminación, habrían elegido ahorrar más. Como solución a este problema, y más en general como una manera de empujar a los empleados para que aumenten su tasa de ahorro, Shlomo Benartzi y yo (Thaler y Benartzi, 2004) presentamos un plan al que llamamos "Ahorre más mañana". En este plan se les da la opción de aumentar su tasa de ahorro a partir de una fecha posterior, idealmente cuando obtengan el siguiente aumento. Una vez que un 
empleado se inscribe en el plan, su tasa de ahorro sigue aumentando hasta que llega a un tope o decide no participar.

Observen que "Ahorre más mañana" es solo un conjunto de FSI. No debería importar que la tasa de ahorro se incremente en pocos meses y no ahora, ni que los incrementos estén vinculados a aumentos del salario, ni que lo predeterminado sea permanecer en el plan, pero, por supuesto, todas estas características ayudan. Posponer el incremento del ahorro al futuro ayuda a quienes son sesgados hacia el presente, vincularlo a los aumentos del salario atenúa la aversión a la pérdida, y que lo predeterminado sea permanecer en el plan da buen uso al sesgo de statu quo. En el primer plan que Benartzi y yo estudiamos (ibíd.), las tasas de ahorro aumentaron más del triple en tres años. En un artículo reciente (Benartzi y Thaler, 2013) estimamos que el escalamiento automático (el término genérico para Ahorre más mañana, en el cual los incrementos del ahorro no siempre están vinculados a aumentos del salario) había elevado los ahorros anuales en $\$ 7.400$ millones.

Una preocupación con respecto a tales programas ha sido que los incrementos que observamos en los ahorros para la pensión debidos a la inscripción automática y Ahorrar más mañana podrían compensarse con reducciones de los ahorros (o aumentos del endeudamiento) en otras cuentas. Pero en Estados Unidos no había un conjunto de datos con el que alguien pudiese probar esta hipótesis. Por fortuna, tales datos existen en Dinamarca, que debido a sus registros del impuesto al patrimonio, durante mucho tiempo ha mantenido buenos datos sobre la riqueza de los hogares. Un reciente artículo de Chetty et al. (2014) utiliza esos datos para responder esta pregunta.

$\mathrm{Su}$ método consiste en ver qué sucede con las tasas de ahorro cuando un empleado pasa a trabajar para un empleador cuyo plan de ahorro para la pensión es más generoso. Utilizando datos de panel con 41 millones de observaciones persona-año esos autores estudian tres tipos de ahorros: aportes patronales a pensiones exentas de impuestos, aportes de los empleados a esas pensiones y ahorros de los empleados en cuentas gravables. Su estrategia de investigación es estudiar a los empleados que han ahorrado una cantidad positiva por su cuenta y luego pasan a una empresa cuyos aportes son al menos 3 puntos porcentuales más altos. En promedio, estos trabajadores reciben un aumento de aportes a la pensión del 5,64\% del ingreso laboral. ¿Los trabajadores aportan menos para compensar esta mayor generosidad de sus empleadores? Sí, pero solo en 56 puntos porcentuales. Y el ahorro en cuentas gravables prácticamente no se modifica. 
Chetty et al. también usan un cambio de política tributaria que ocurrió en el periodo para el que tienen datos. Este experimento natural les permitió comparar la efectividad del subsidio tributario a los aportes para pensiones a fin de fomentar el ahorro para la jubilación con los efectos de características de diseño como el aporte patronal. Ese cambio legal fue una reducción del subsidio al ahorro para la jubilación al quintil superior de la distribución del ingreso. Incluso en este grupo relativamente rico, la gran mayoría no reaccionó en absoluto a la reducción del subsidio; eran "ahorradores pasivos". Cerca del $20 \%$ de este segmento reaccionó y eliminó todos sus aportes a los planes de exentos de impuestos, pero no gastó ese dinero; solo lo trasladó a líneas de ahorro gravables. Esto lleva a una conclusión notable. Cada $\$ 1$ de gasto tributario en ahorros para pensiones solo produjo un centavo de aumento del ahorro. Lo que determina la tasa de ahorro no es la política fiscal sino las características de diseño de los planes de pensiones del empleador, es decir, los FSI.

Hay muchos otros ejemplos del poder potencial de los factores de comportamiento en el análisis de políticas, pero resumirlos sería una pérdida tiempo. No puedo hacer un mejor trabajo que el que hizo Raj Chetty el año pasado en su conferencia Ely: "La economía del comportamiento y la política pública: una perspectiva pragmática" (2015). Respaldo totalmente su opinión de que la mejor manera de proceder es dejar de discutir sobre principios teóricos y ponerse a trabajar para averiguar cuál es la mejor manera de entender el mundo.

\section{CONCLUSIÓN}

En este ensayo hay un tema central: es hora de acoger plenamente lo que yo llamaría economía basada en la evidencia. Esto no debería ser difícil de vender. Los economistas usan las técnicas estadísticas más sofisticadas de toda ciencia social, tienen acceso a bases de datos cada vez más grandes y ricas, y han aceptado muchos métodos nuevos, desde experimentos (de laboratorio y de campo) hasta imágenes cerebrales y aprendizaje automático. Además, la economía se ha convertido en una disciplina cada vez más empírica. Hamermesh (2013) encuentra que el porcentaje de artículos "teóricos" en las principales revistas de economía se redujo del 50,7\% en 1963 al 19,1\% en 2011. Es indudable que somos una disciplina empírica; así que aceptémoslo.

Vista en este contexto, la economía del comportamiento es solo una parte de la creciente importancia del trabajo empírico en economía. No hay nada único en incorporar factores psicológicos como el encuadre, el autocontrol y la justicia en el análisis económico. Si esos factores nos 
ayudan a entender mejor el mundo y a mejorar las predicciones del comportamiento, ¿por qué no usarla así como usamos otras nuevas fuentes de datos, como las búsquedas en la red o los marcadores genéticos?

En este sentido, creo que es hora de dejar de pensar en la economía del comportamiento como una especie de revolución. La economía del comportamiento se debería considerar, más bien, como un retorno al tipo de disciplina de mente abierta e intuitivamente motivada inventada por Adam Smith y ampliada por herramientas y bases de datos estadísticos cada vez más potentes. Esta disciplina basada en la evidencia se fundamentará teóricamente, pero no de un modo que restrinja nuestra atención únicamente a aquellos factores que se puedan derivar de nuestras tradiciones normativas tradicionales. De hecho, intuyo que estamos al comienzo de una nueva oleada de desarrollos teóricos que se hacen posibles simplemente al centrar la atención en el estudio de los Humanos y no de los Econos.

Si la economía se desarrolla siguiendo esa línea, el término "economía del comportamiento" eventualmente desaparecerá de nuestro léxico. Toda economía se referirá al comportamiento como lo requiera el tema, y en consecuencia tendremos un enfoque de la economía que arrojará un $\mathrm{R}^{2}$ más alto.

\section{REFERENCIAS BIBLIOGRÁFICAS}

Arrow, K. J. (1986). Rationality of self and others in an economic system. Journal of Business, 59(4), S385-S399.

Ashraf, N. C. et al. (2005). Adam Smith, behavioral economist. Journal of Economic Perspectives, 19(3), 131-145.

Atkinson, A. B. et al. (2011). Top incomes in the long run of history. Journal of Economic Literature, 49(1), 3-71.

Barberis, N. y Thaler, R. H. (2003). A survey of behavioral finance. Handbook of the Economics of Finance. Vol. 1, parte B, 1053-1123.

Benartzi, S. y Thaler, R. H. (2013). Behavioral economics and the retirement savings crisis. Science, 339(6124), 1152-1153.

Ben-David, I., Graham, J. R. et al. (2013). Managerial miscalibration. Quarterly Journal of Economics, 128(4), 1547-1584.

Black, F. (1986). Noise. Journal of Finance, 41(3), 529-543.

Camerer, C. (1997). Labor supply of New York City cabdrivers: One day at a time. Quarterly Journal of Economics, 112(2), 407-441.

Card, D., Heining, J. et al. (2013). Workplace heterogeneity and the rise of West German wage inequality. Quarterly Journal of Economics, 128(3), 967-1015.

Case, K. E., Shiller, R. J. et al. (2012). What have they been thinking? Home buyer behavior in hot and cold markets. NBER working paper, 18400.

Chetty, R. (2015). Behavioral economics and public policy: A pragmatic perspective. American Economic Review, 105(5), 1-33. 
Chetty, R., Friedman, J. N. et al. (2014). Active vs. passive decisions and crowd-out in retirement savings accounts: Evidence from Denmark. Quarterly Journal of Economics, 129(3), 1141-1219.

Clark, J. M. (1918). Economics and modern psychology: I and II. Journal of Political Economy, 26(1), 1-30.

Crawford, V. P. y Meng, J. (2011). New York City cab drivers' labor supply revisited: Reference-dependent preferences with rationalexpectations targets for hours and income. American Economic Review, 101(5), 1912-1932.

De Bondt, W. F. y Thaler, R. H. (1985). Does the stock market overreact? Journal of Finance, 4O(3), 793-805.

De Bondt, W. F. y Thaler, R. H. (1987). Further evidence on investor overreaction and stock market seasonality. Journal of Finance, 42(3), 557-581.

DellaVigna, S. y Malmendier, U. (2006). Paying not to go to the gym. American Economic Review, 96(3), 694-719.

Dickens, W. T. y Katz, L. F. (1986). Interindustry wage differences and industry characteristics. NBER working paper, 2014.

Fama, E. F. y French, K. R. (1993). Common risk factors in the returns on stock and bonds. Journal of Financial Economics, 33(1), 3-56.

Farber, H. S. (2015). Why you can't find a taxi in the rain and other labor supply lessons from cab drivers. Quarterly Journal of Economics, 130(4), 1975-2026.

Fehr, E. y Schmidt, K. M. (1999). A theory of fairness, competition, and cooperation. Quarterly Journal of Economics, 114(3), 817-868.

Fisher, I. (1930). The theory of interest: As determined by impatience to spend income and opportunity to invest it. Nueva York: MacMillan.

Friedman, M. (1953). The methodology of positive economics. En M. Friedman (ed.), Essays in positive economics (pp. 3-43). Chicago: University of Chicago Press.

Fudenberg, D. y Levine, D. K. (2006). A dual self-model of impulse control. Harvard Institute of Economic Research, working paper 2112.

Graham, B. (1973). The intelligent investor. A book of practical counsel. Nueva York: Harper \& Row.

Grether, D. M. y Plott, C. R. (1979). Economic theory of choice and the preference reversal phenomenon. American Economic Review, $69(4), 623-638$.

Hamermesh, D. S. (2013). Six decades of top economics publishing: Who and how? Journal of Economic Literature, 51(1), 162-172.

Hogarth, R. M. y Reder, M. W. (1986). The behavioral foundations of economic theory. Journal of Business, 59(4), S181-S505.

Hogarth, R. M. y Reder, M. W. (1987). Rational choice: The contrast between economics and psychology. Chicago: University of Chicago Press.

Jensen, M. C. (1968). The performance of mutual funds in the period 1945-1964. Journal of Finance, 23(2), 389-416.

Kahneman, D. y Tversky, A. (1979). Prospect theory: An analysis of decision under risk. Econometrica, 47(2), 263-291.

Kaplan, S. N., Klebanov, M. M. et al. (2012). Which ceo characteristics and abilities matter? Journal of Finance, 67(3), 973-1007. 
Katona, G. (1951). Psychological analysis of economic behavior. Nueva York: McGraw-Hill.

Katona, G. (1953). Rational behavior and economic behavior. Psychological Review, 60(5), 307-318.

Keynes, J. M. (1936). The general theory of employment, interest, and money. Londres: Macmillan.

Krueger, A. B. y Summers, L. H. (1988). Efficiency wages and the interindustry wage structure. Econometrica, 56(2), 259-293.

Laibson, D. (1997). Golden eggs and hyperbolic discounting. Quarterly Journal of Economics, 112(2), 443-477.

Lakonishok, J., Shleifer, A. et al. (1994). Contrarian investment, extrapolation, and risk. Journal of Finance, 49(5), 1541-1578.

Lamont, O. A. y Thaler, R. H. (2003a). Anomalies: The law of one price in financial markets. Journal of Economic Perspectives, 17(4), 191-202.

Lamont, O. A. y Thaler, R. H. (2003b). Can the market add and subtract? Mispricing in tech stock carve-outs. Journal of Political Economy, 111(2), 227-268.

Lester, R. A. (1946). Shortcomings of marginal analysis for wage-employment problems. American Economic Review, 36(1), 63-82.

Lichtenstein, S. y Slovic, P. (1971). Reversals of preference between bids and choices in gambling decisions. Journal of Experimental Psychology, 89(1), 46-55.

Lichtenstein, S. y Slovic, P. (1973). Response-induced reversals of preference in gambling: An extended replication in Las Vegas. Journal of Experimental Psychology, 101(1), 16-20.

Loewenstein, G. (1992). The fall and rise of psychological explanations in the economics of intertemporal choice. En G. Loewenstein $\mathrm{y} \mathrm{J}$. Elster (eds.), Choice over time (pp. 3-34). Nueva York: Russell Sage Foundation.

Lucas, R. E. Jr. (1976). Econometric policy evaluation: A critique. Carnegie-Rochester Conference Series on Public Policy, 1, 19-46.

Machlup, F. (1946). Marginal analysis and empirical research. American Economic Review, 36(4), 519-554.

Madrian, B. C. y Shea, D. F. (2001). The power of suggestion: Inertia in 401(k) participation and savings behavior. Quarterly Journal of Economics, 116(4), 1149-1187.

Mehra, R. y Prescott, E. C. (1985). The equity premium: A puzzle. Journal of Monetary Economics, 15(2), 145-161.

Mishel, L. y Davis, A. (2015). Top CEOs make 300 times more than typical workers. Economic Policy Institute, Issue Brief 399, [http:// www.epi.org/files/2015/top-ceos-make-300-times-more-than-typicalworkers.pdf].

Muth, J. F. (1961). Rational expectations and the theory of price movements. Econometrica, 29(3), 315-335.

O’Donoghue, T. y Rabin, M. (1999). Procrastination in preparing for retirement. H. J. Aaron (ed.), Behavioral dimensions of retirement economics (pp. 125-156). Washington DC: Brookings Institution. 
Pareto, V. (2014). Manual of political economy: A critical and variorum translation edition. En A. Montesano, A. Zanni et al. (eds.), Economic equilibrium (pp. 173-190). Oxford, UK: Oxford University Press.

Pigou, A. C. (1920). The economics of welfare. [http://oll. libertyfund. org/title/1410].

Piketty, T. (2014). Capital in the twenty-first century. Cambridge, Mass.: Harvard University Press.

Rabin, M. (1993). Incorporating fairness into game theory and economics. American Economic Review, 83(5), 1281-1302.

Rabin, M. (2013). An approach to incorporating psychology into economics. American Economic Review, 103(3), 617-622.

Schelling, T. C. (1984). Self-command in practice, in policy, and in a theory of rational choice. American Economic Review, 74(2), 1-11.

Shiller, R. J. (1984). Stock prices and social dynamics. Brookings Institution Press, 1984(2), 457-510.

Simon, H. A. (1955). A behavioral model of rational choice. Quarterly Journal of Economics, 69(1), 99-118.

Simon, H. A. (1957). Models of man: Social and rational. Mathematical essays on rational human behavior in a social setting. Oxford, UK: Wiley.

Simon, H. A. (1987). Behavioural economics. En J. Eatwell, M. Milgate et al. (eds.), The new Palgrave: $A$ dictionary of economics. Londres: Palgrave Macmillan.

Slichter, S. H. (1950). Notes on the structure of wages. Review of Economics and Statistics, 32(1), 80-91.

Smith, A. (1981). The theory of moral sentiments [1759]. Indianapolis: Liberty Classics.

Smith, A. (1981). An inquiry into the nature and causes of the wealth of nations [1776]. Indianapolis: Liberty Classics.

Strotz, R. H. (1955). Myopia and inconsistency in dynamic utility maximization. Review of Economic Studies, 23(3), 165-180.

Thaler, R. H. (1980). Toward a positive theory of consumer choice. Journal of Economic Behavior E Organization, 1(1), 39-60.

Thaler, R. H. (1989). Interindustry wage differentials. Journal of Economic Perspectives, 3(2), 181-193.

Thaler, R. H. (2015). Misbehaving: The making of behavioral economics. Nueva York: W. W. Norton \& Company.

Thaler, R. H. y Shlomo, B. (2004). Save more tomorrow: Using behavioral economics to increase employee saving. Journal of Political Economy, 112(1), S164-S187.

Thaler, R. H. y Shefrin, H. M. (1981). An economic theory of selfcontrol. Journal of Political Economy, 89(2), 392-406.

Tversky, A. y Kahneman, D. (1974). Judgment under uncertainty: Heuristics and biases. Science, 185(4157), 1124-1131.

Van den Assem, M. J., Van Dolder, D. et al. (2012). Split or steal? Cooperative behavior when the stakes are large. Management Science, $58(1), 2-20$.

Von Neumann, J. y Morgenstern, O. (1947). Theory of games and economic behavior. Princeton: Princeton University Press.

Vulkan, N. (2000). An economist's perspective on probability matching. Journal of Economic Surveys, 14(1), 101-118. 